\title{
PLANEACIÓN POR ESCENARIOS EN LA FAC
}

Mikell lbarta Fernández*

\section{RESUMEN:}

El futuro siempre ha sido el objeto de estudio cuando tratamos de garantizar nuestra supervivencia, conocerlo es sin duda una ventaja inmejorable frente a los demás y al entorno. Es imposible adivinar el futuro pero es posible analizar el pasado y presente para intentar descubrir la evolución de la historia.

La prospectiva cree que el futuro se explica desde el presente, y éste a su vez del pasado, esta relación causa-efecto permite construir nuestro mañana, valiéndose del análisis de los factores sociales, económicos, culturales, ambientales y políticos que afectan el desarrollo histórico, Llevándonos a una visión sistémica $v$ compleja del mundo. Construir el mañana tiene al ser humano y a sus instituciones como protagonistas de su propia historia

\section{ABSTRACT:}

The future has always been the object of study when we try to guarantee our survival, because knowing the future undoubtedly gives us an unsurpassable advantage over others and the environment. It is impossible to guess the future but it is possible to analyze the past and present to try to discover the evolution of the history. Prospective believes that the future is explained from the present, and this in turn from the past. This relation allows us to build our tomorrow, through the analysis of social, economic, cultural, environmental and political factors that undoubtedly affect historical development, tanking us to a systemic and complex vision of the world. Prospective makes human beings and their institutions into protagonists of their own history, to build the tomorrow.

Las civilizaciones que han liderado al mundo siempre se han caracterizado por ser dueñas de su futuro, nunca esclavas de las tendencias; su ventaja no se encuentra en la anticipación de los problemas, está en la proactividad al enfrentarlos. Conocer los probables futuros que enfrentarían las organizaciones garantiza sin duda una ventaja inmejorable frente a los demás y al entorno, pero ésta se maximiza cuando se entra a diseñar el futuro que se quiere vivir partiendo de las acciones que se realizan hoy.

La prospectiva como indisciplina ${ }^{1}$ o disciplina intelectual nos da un mensaje voluntarista y antideterminista, invitándonos a pensar de una manera distinta, sacudiendo viejos paradigmas y presupuestos sobre lo que sería un futuro que aparentemente ya está escrito. Esta labor tiene en los hombres y en las organizaciones ${ }^{2}$ a los sujetos que llevarán la iniciativa colectiva de construir futuro.

\footnotetext{
*Ingeniero Mecánico de la Universidad Nacional de Colombia, cuenta con una Maestría en Administración de Empresas con Énfasis en Planeación y una Especialización en Planeación Estratégica y Prospectiva. Se ha desempeñado en cargos como Ingeniero, Docente y Asesor en Planeación Estratégica. Dictó el primer diplomado en Prospectiva que la FAC realizó dando como resultado los Escenarios Probables del Conflicto y la FAC para el 2016

1 GODET, Michel. De la anticipación a la acción. Bogotá: Alfaomega, 1990. p 25

2 Ibid.,p17.
} 


\section{LOGISTICA}

Es evidente la necesidad de un modelo que permita anticipar y construir nuestro futuro. ¿Por qué anticipar? Si conocemos de antemano los movimientos de nuestro entorno tendremos una ventaja invaluable frente a la competencia o enemigo, podremos preparar decisiones y estrategias para responder sin caer en el recurso de la improvisación. ¿Por qué construir? Anticipar es sólo el primer paso, la estrategia primaria. Si realmente queremos subsistir y crecer en un mundo global con sus interrelaciones complejas e interminables debemos estar en la capacidad de influenciar y de alguna forma construir el futuro en el que nos desenvolveremos en algún tiempo, tornándolo lo más positivo y apropiado posible para nosotros y nuestra institución.

¿Pero qué es lo que se construye o se anticipa? La respuesta es sencilla: un abanico de escenarios que podrían suceder. Desde el punto de vista de la prospectiva un escenario no es la realidad futura ${ }^{3}$, sino una forma de presentar la evolución de la situación actual a los futuros probables, es una imagen de futuro, explicada mediante la situación actual y los sucesos que acontecerían.

La principal amenaza en nuestro país ha sido por muchos años el conflicto interno, que ha involucrado a distintos agentes generadores de violencia como los grupos narcoterroristas $y$

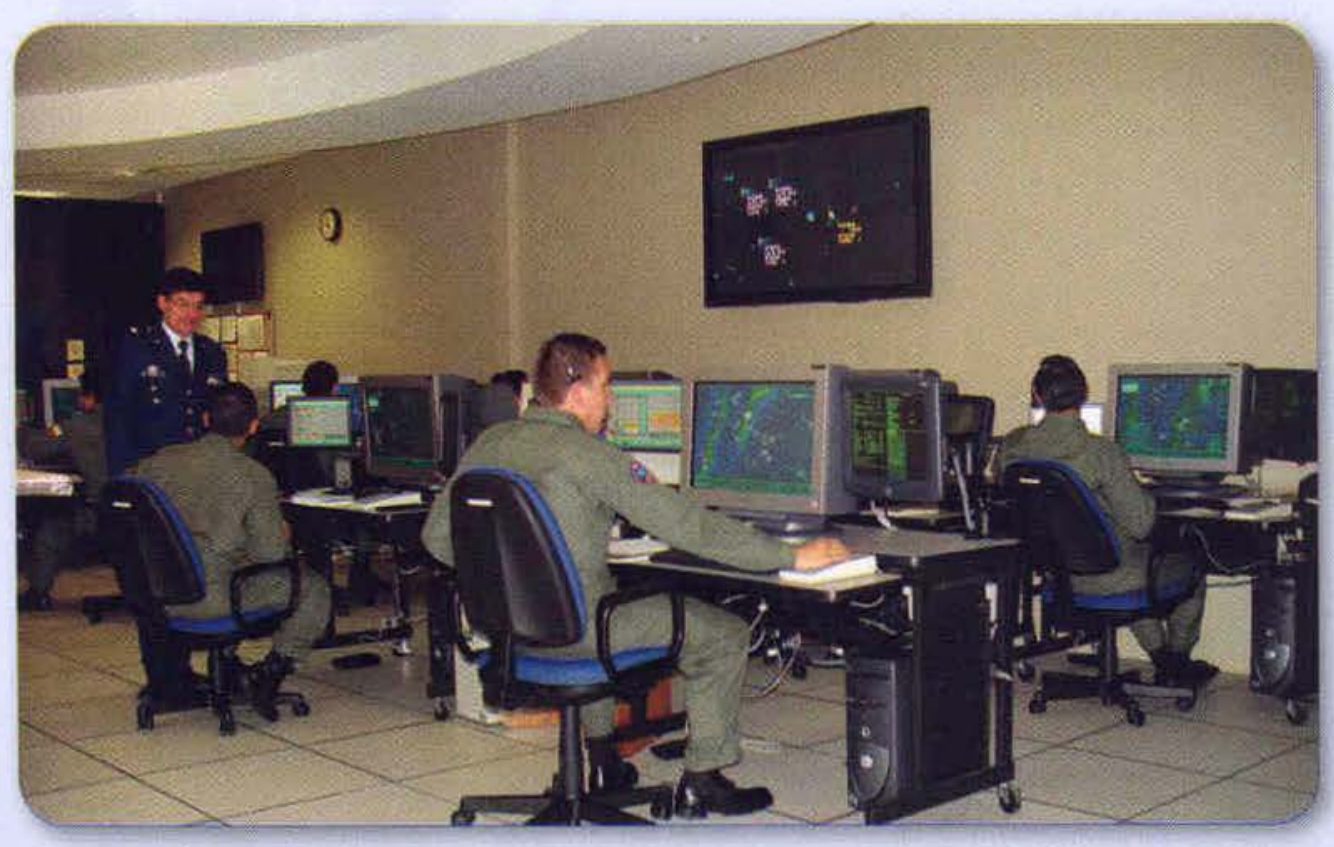

los paramilitares. El accionar de tales agentes generadores de violencia ha afectado las relaciones económicas, sociales y políticas con los países vecinos, obligando al gobierno nacional y su diplomacia a movilizar esfuerzos para mantener intactos los convenios económicos y los lazos de fraternidad entre los pueblos.

A este panorama nacional, es necesario agregar la situación política inestable que vive Latinoamérica, donde varios de sus gobiernos tienden hacia un modelo socialista, alejándose de la política de los Estados Unidos, generando alianzas económicas para enfrentar los Tratados de Libre Comercio (TLC) que los considera lesivos para el crecimiento y desarrollo de la región.

Ante esta situación inquietante para nuestro país y de hecho para nuestras fuerzas militares, es importante estar preparados para los cambios de las amenazas actuales y futuras, involucrando a sus procesos de planificación más herramientas que per- 
mitan vislumbrar ese futuro que se podría presentar. Es ahí donde se hace necesaria la construcción de escenarios mediante la aplicación de una herramienta como la prospectiva estratégica, que brinde un panorama más aproximado sobre el futuro que se aproxima rápidamente.

La Fuerza Aérea Colombiana, continuando con su proceso de planeación estratégica, reconoció la necesidad de incorporar en su modelo de planeación una herramienta que permitiera tener una visión clara de la evolución del presente hacia el futuro, y en el primer trimestre del 2006 se inició el proceso de implantación de la Prospectiva para suplir esta necesidad inició a través de un Diplomado con Oficiales y Suboficiales de las distintas áreas funcionales.

Como resultado de este Diplomado se generó el documento "FAC y CONFLICTO ARMADO 2016", el cual contiene un conjunto de escenarios que podrían ser realidad dependiendo de la evolución de ciertas variables del entorno social, político y económico Colombiano.

A grandes rasgos, el modelo prospectivo se resume en 4 fases. La primera consta del análisis y modelamiento del fenómeno en estudio (en nuestro caso el conflicto). La segunda analiza los actores sociales que están involucrados y defienden sus intereses alrededor del modelo (comportamientos y alianzas). Con los resultados anteriores se proyectan los escenarios probables en la tercera fase, escogiendo el escenario apuesta, convirtiéndolo en el objetivo a materializar, mediante las estrategias que se plantean y organizan en la última fase.

¿Pero cómo se integra la prospectiva a la planeación estratégica de la FAC? La prospectiva señala el objetivo macro de la Fuer- za, genera una visión más clara y compleja de la realidad que podríamos tener en unos años, y la diferencia de la realidad que queremos tener, el plan estratégico tiene como propósito alejarnos de las tendencias y llevarnos a materializar nuestros sueños.

Este escenario se transcribe a la metodología Balanced Scorecard para que el escenario apuesta sea convertido en objetivos e iniciativas, y poder realizar mediante esta herramienta el seguimiento, control, evaluación y comunicación del plan estratégico.

La Fuerza Aérea cuenta actualmente con una nueva herramienta que se articula a su modelo y que colabora con la búsqueda de la excelencia en la administración de recursos, enfocándola en objetivos que contribuirán a lograr un mejor país en el mediano plazo, y preparándola para convivir exitosamente con la incertidumbre de un mundo cambiante y algunas veces caótico.

\section{BIBUIपGRAFIA}

BERGER, Gaston. Phenoménologie du temps et prospective. 18 Edición. Paris: Presses Universitaries de France, $1964.360 \mathrm{p}$

DE JOUVENEL, Bertrand. El arte de la conjetura. 18 Edición. Madrid: Rialpe, 1996, 250 p.

GODET, Michel. De la anticipacién a la acción. 18 Edición. Bogota: Altaomega. 1990. $360 \mathrm{p}$

GODET, Michel. Manuel de Prospective Stratégique. 18 Edición. Paris: Dunod. 1999 $420 \mathrm{p}$. 